\title{
Issues and Tensions in Island Heritage Management: A Case Study of Motuihe Island, New Zealand
}

David Bade

PhD Candidate, School of Environment

University of Auckland

New Zealand

dbad008@aucklanduni.ac.nz

\begin{abstract}
This paper draws on a New Zealand case study, Motuihe Island, to examine the challenges of conserving cultural heritage in places renowned for natural heritage values. In keeping with the broader trend toward the ecological restoration of islands close to Auckland, Motuihe Island is undergoing conversion into an ecosystem of native flora and fauna. Issues and tensions relating to the management of natural and cultural heritage will be discussed and influencing aspects investigated: the nature/culture dualism, the effect of New Zealand's history and identity, and the influence of islandness on heritage management.
\end{abstract}

Keywords: Auckland, culture, heritage management, islandness, Motuihe Island, nature, New Zealand

(C) 2010 - Institute of Island Studies, University of Prince Edward Island, Canada

\section{Introduction}

The archipelago of New Zealand was the last significant landmass to be settled by humans. Polynesian settlement (from the $14^{\text {th }}$ century) and European settlement (from the mid-19 $9^{\text {th }}$ century) has left its mark on the New Zealand landscape, creating a mesh of past environments and settlement (Young, 2004). This legacy of human interaction with the landscape is considered as heritage which needs to be conserved in the present for future generations. In New Zealand, and indeed around the world, management of this heritage is split into cultural heritage - places displaying relics of past settlements, developments in architecture and technology, and examples of cultural traditions - and natural heritage aspects of nature such as species of plants and animals, unique habitats and geological features (Meadows \& Ramutsindela, 2004). New Zealand's cultural heritage, including archaeological features from Maori settlement (the indigenous people of New Zealand) and buildings and structures from Pakeha (New Zealand European) settlement, is managed by state agencies such as the Department of Conservation (DoC) and the New Zealand Historic Places Trust (NZHPT). Despite state regulation and protection, however, there have been significant changes to New Zealand's natural heritage. Massive deforestation, the creation of grasslands and the introduction of non-native plant and animal species have led to transformations of New Zealand's environment resulting in numerous native species becoming threatened or even extinct (Pawson \& Brooking, 2002). State agencies such as DoC conserve and preserve remnants of New Zealand's natural heritage on the mainland and on off-shore islands within New Zealand's territorial boundaries. 
Near-shore islands in New Zealand often have considerable histories relating to Maori and Pakeha settlement, including intensive farming and recreation since the mid-1800s. Nearshore (and off-shore) islands in New Zealand also have a history of being designated as nature sanctuaries. In fact, some of the very first New Zealand nature sanctuaries were established on islands in the 1890s: Hauturu (Little Barrier) Island, Resolution Island and Kapiti Island (Young, 2004). Inherent characteristics of islands (islandness), including such features as separateness, boundedness, isolation, vulnerability and smallness, make islands prime candidates for ecological restoration. Additionally, islands are places where natural heritage can be emphasized. Recently, ecological restorations of near-shore islands in New Zealand have become common, especially in the Hauraki Gulf, close to Auckland, New Zealand's largest city (population 1.3 million people). These islands are perceived as places that should showcase New Zealand's flora and fauna. Since the late 1980s, numerous community trusts have been formed with the aim to restore various islands in the Hauraki Gulf into places where cultural and natural heritage can be preserved, experienced, and enjoyed. Currently, there are island community trusts on Great Barrier, Kaikoura, Kawau, Hauturu, Motuihe, Motuora, Motutapu, Rangitoto, Tiritiri Matangi, and Waiheke Islands (Figure 1). Typically, the trusts manage an island of their own, or in some cases part of an island, in partnership with DoC, New Zealand's foremost state authority governing the management of natural and cultural heritage. The trusts are managed by volunteers from Auckland and rely on financial support from state funds or corporate sponsorship.

Although acknowledging cultural heritage, island restoration plans often have a very strong natural heritage focus. This focus has emerged largely at the cost of cultural heritage and is a concern among those involved in the heritage management of the Hauraki Gulf (Hauraki Gulf Forum, 2008; Ministry for the Environment, 2004). Literature and anecdotal evidence suggests that natural heritage tends to take precedence over cultural heritage in New Zealand. Such an issue can be particularly seen on islands, such as those in the Hauraki Gulf, that are designated as nature sanctuaries or are afforested to provide habitat for rare and endangered birds and reptiles. The challenge is ensuring the objectives of natural heritage restoration are met without compromising the cultural heritage.

Heritage management in New Zealand is therefore confronted with a major issue: how to achieve a balance between natural and cultural heritage. This dilemma, however, highlights the way nature and culture is separated. This distinction is known as the nature/culture dualism and is deeply entrenched into heritage management, not only in New Zealand but also around the world. In this paper, the implications of the nature/culture dualism within heritage management will be investigated by examining the way cultural heritage on nearshore islands is managed where the focus is primarily on the restoration and preservation of natural heritage. The nature/culture dualism often means that, in areas where natural heritage is emphasized, cultural heritage is not adequately recognized, in order to promote the place as natural. 
Figure 1: Map showing the Islands of the Hauraki Gulf (DoC, 2010)

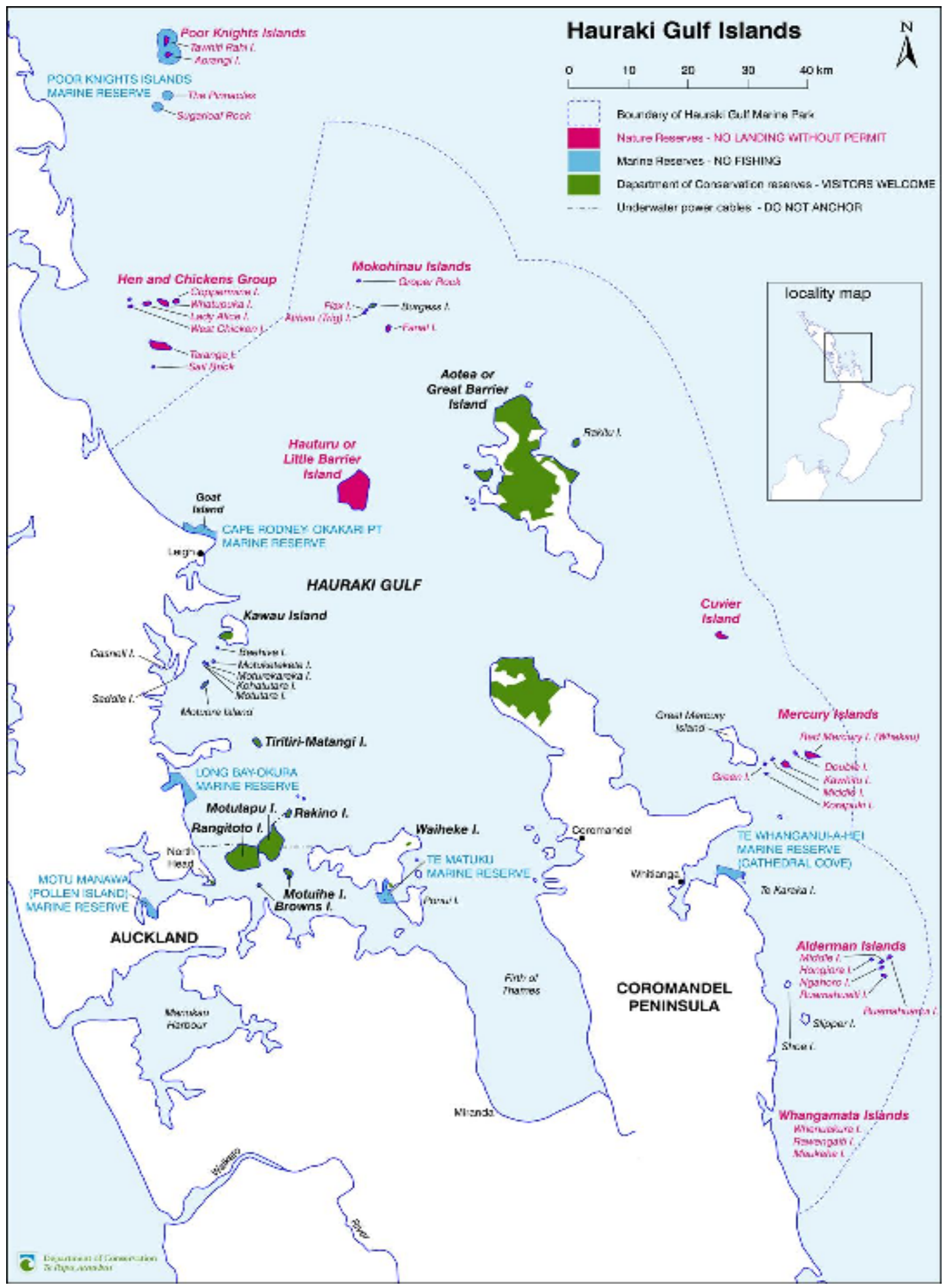


The following analysis draws on a New Zealand case study, Motuihe Island, to highlight and discuss issues and challenges associated with management of the island's heritage. The author has visited the island on numerous occasions, interviewed members of the Motuihe Trust and various heritage managers, has taken part in tree-planting and weeding activities, and acted as a volunteer heritage guide on the island. Additional information in this paper has been sourced from the Department of Lands and Survey, Department of Conservation archives, as well as from interviews undertaken with members of the Motuihe Trust, the Department of Conservation and the New Zealand Historic Places Trust.

The history of Motuihe Island will be briefly outlined below before three main examples where management of the natural and cultural heritage of the island come into conflict and tension are discussed. These are: (a) ecological restoration tensions with archaeological preservation; (b) historical - but exotic - trees being treated as weeds and removed; and (c) the impact of ecological restoration on seaside recreation. The main underlying influences of these issues will then be discussed: the nature/culture dualism in heritage management, the effect of New Zealand's history and identity on heritage management, and the influence of islandness. The paper will conclude with consideration of how such issues and tensions have been resolved.

\section{The Hauraki Gulf and Motuihe Island}

The Hauraki Gulf encompasses the body of water between the Auckland isthmus in the west and the Coromandel Peninsula in the east (Figure 1). There are over fifty islands in the Hauraki Gulf and these have a diverse array of uses and functions, from the wildlife sanctuary of Little Barrier Island to the growing suburb of Waiheke Island. The Hauraki Gulf islands are accessible and picturesque, and hold a special place in the lives and identity of Aucklanders, particularly because there is a strong tradition of recreational use of the islands. The proximity of the inner Gulf islands to the large population base of Auckland has also, to a great extent, brought about the formation of the various island community trusts described above, which have strong voluntary support for their activities.

Motuihe Island is an uninhabited 179-hectare recreation reserve under DoC management, situated in the inner Hauraki Gulf (Figure 2). As a recreation reserve, the entire island of Motuihe is open to the public. It is readily accessible from Auckland, at a distance of only $15 \mathrm{~km}$, or a 30-minute ferry ride, from downtown Auckland. The Motuihe Project was developed by the Motuihe Trust voluntary organisation (formed 2000) in partnership with DoC with the aim to "restore, enhance and protect the indigenous flora and fauna and the significant Maori and historic sites of Motuihe Island" (Hawley, 2005: 1). The project intends to transform Motuihe from a predominantly farm landscape into an indigenous forested landscape, where its natural heritage is restored and its cultural and historical heritage is brought to life (Hawley, 2005). The activities of the Motuihe Project highlight many issues regarding the conservation of cultural heritage in places emphasized for natural values that are particularly pertinent to New Zealand's islands. 
Island Heritage Management: Motuihe Island

Figure 2: Aerial Photograph of Motuihe Island in 1999. Reproduced with permission from the Department of Conservation and John Hawley.

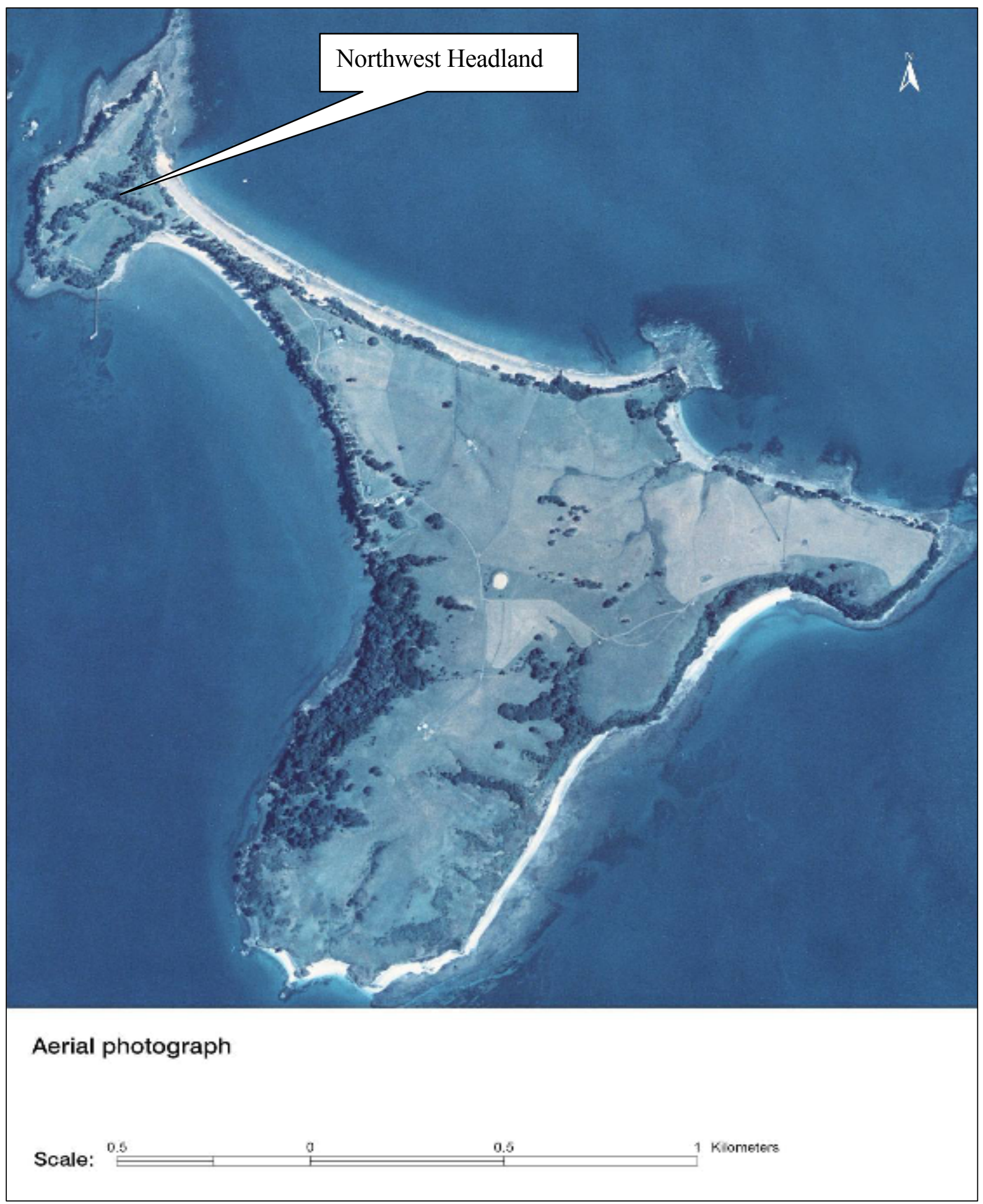




\section{Brief History of Motuihe Island}

Motuihe Island has a long and diverse environmental and human history. Motuihe once supported a mixed conifer-hardwood native forest (Heiss-Dunlop, 2004). However, after human settlement the island environment was systematically transformed into one almost completely dominated by pasture and exotic species. Today there are only three sections of remnant coastal bush (Figure 2) and most of these are likely to be of secondary growth from the $19^{\text {th }}$ century, although there are a number of ancient Pohutakawa (Metrosideros excelsa) trees (Esler, 1974; de Lange \& Crowcroft, 1999).

Motuihe Island was first occupied by Maori in the $13^{\text {th }}$ century (Graham, 1930; Walsh, 1937). There is a complex archaeological landscape associated with Maori settlement, with 62 sites officially recorded (Dodd, 2003a). The first official purchase of the island by a European was on 5 November 1839 by the missionary William Fairburn, who purchased the island from three Maori chiefs. There were then a series of sales until the island was sold to two prominent early Auckland colonists, William Brown and John Logan Campbell, for £220 in 1840 (Walsh, 1937). During this early period, Motuihe was farmed by Maori workers under a European farm manager. A number of exotic trees were planted in the late nineteenth century and early twentieth century which are present today. Most noticeable are the lines of Norfolk Pines running on the isthmus of the island (Figure 2).

In 1872, the Board of Health of the Port of Auckland set up a quarantine station on Motuihe for immigrant ships. The cemetery on the northwest headland relates to this period. The larger southern end of the island (mainly farmland) was used by the Department of Agriculture as an animal quarantine station from 1892 until 1941 (Wood, 2006). The animal quarantine station was well used up to 1930 , being permanently closed off from the public. However, the human quarantine station was only occasionally called into service and was often used for other purposes in the early twentieth century.

During the First World War (1914-1918), the buildings on the northwest headland were reused as an internment camp for enemy aliens. A number of German and Austrian residents of New Zealand and Samoa, who were considered to be a possible security risk, and a few prisoners of war, notably the German raider Count Felix von Luckner, were interned on the island. The best known story from this internment camp era is the audacious escape of eleven German internees led by von Luckner (Bade, 2006). Because the quarantine station was seldom used from the 1920s, the quarantine building complex became a children's health camp under the Community Sunshine Association in 1929 (Tennant, 1994).

With the outbreak of World War II and the urgent need to train more naval personnel, the buildings at the northwest headland on Motuihe were converted into a navy training establishment during 1941, named HMNZS Tamaki (NZH, 1961; Brassey, n.d.). By the end of World War II, over six thousand people - almost two thirds of all New Zealanders who were engaged in naval service during that time - went through training on the island (Yarwood, 1997; DoC, 2001). The only buildings or structures surviving on the northwest headland are the naval surgeon's residence, the Ministry of Works building, a water tank, and the salt water tower, which supplied water for lavatories and fire fighting purposes. 
The two most sustained utilisations of the island have been the use of the greater part of the island as a farm and the use of the Motuihe beaches by the public for recreation. The island was farmed for over 165 years since European ownership. From 1930 to 2005, the island was managed as a concessionaire farm. Farmers leased the land from the Department of Lands and Survey (L\&S), and later DoC, and farmed the island with a combination of cattle and sheep. A proportion of the profits was used for maintaining visitor infrastructure, such as fences and the wharf. During this period, apart from during World War II, the beaches of the island could be used by the public for recreation. The island was essentially a farmpark. Motuihe Island has continued to be a highly popular destination for day-trippers, arriving by private boat or public ferry, gaining the label "gem of the Gulf' (Deluxe Charters, 2010).

During the 1970s and 1980s, weeds and mammalian pests, especially rabbits, increasingly became a problem on the island. In the 1990s, a community trust was formed with the main objective to ecologically restore the island, emulating other island restorations in the Hauraki Gulf, in particular, Tiritiri Matangi (Rimmer, 2004). However, an important part of the planned programme, and one which was emphasized in the initial discussion about the goal of the trust, was the human element of the history of the island. The intention was not to lose touch with the people who had lived there and the long history of recreational use of the island. In 2005, the Motuihe Trust was officially formed and, with the help of hundreds of volunteers, has set about its work to restore, enhance, and protect both the natural and cultural heritage of Motuihe (Motuihe Trust, 2010).

\section{Issues and Tensions in the Heritage Management of Motuihe}

Since its formation, the Motuihe Trust has actively worked towards its primary aim of an ecological restoration of the island. Led by passionate and hard-working organisers from the Motuihe Trust, volunteers have planted over 140,000 native trees and shrubs, and many exotic weeds have been removed during weekend and occasional mid-week volunteer programmes since 2005. A mammalian pest eradication programme has removed all rodents and rabbits from the island. Motuihe Island was declared pest-free in January 2005, after earlier being declared free of rats and mice in 1996 (Rudman, 2008). Since then, three rare and endangered native bird species, the North Island Saddleback (Philesturnus carunculatus) (11 August 2005), the Red-crowned Kakariki (Cyanoramphus novaezelandiae) (17 May 2008), and the Little Spotted Kiwi (Apteryx owenii) (21 March 2009) have been (re-)introduced to the island through translocation programmes from Tiritiri Matangi, Little Barrier, and Kapiti Island respectively.

It appears that the natural heritage of Motuihe tends to dominate over cultural heritage (Bade, 2008). What does this mean for the cultural heritage of the island? The dominance of natural heritage over cultural heritage is illustrated below by way of three particular issues which have arisen from the management of the ecological restoration of the island: with regard to archaeology, exotic historical trees, and recreation. 


\section{Managing archaeology with ecological restoration}

One of the major issues to emerge in heritage management is the tension between achieving goals of ecological restoration whilst protecting the (in-ground) archaeological sites on the island associated with Maori occupation. According to Jones (2007: 5) archaeological sites are a valuable heritage resource that "deserves to be protected and conserved for future generations." However, loss and damage can occur to archaeological sites as a result of three activities related to ecological restoration: the removal of grazing animals which renders the archaeological sites less visible and facilitates weed growth; the planting of trees which can potentially damage sites; and track-making which can cut through and damage sites.

Once grazing has ceased in an area, as on Motuihe, features of archaeological sites become less visible as a result of grass growth (Dodd, 2002). Such a situation has the potential to create problems if archaeological sites are not accurately identified. Considerable communication and a joint understanding of the process involved in activities is required between tree-planting organizers and archaeology managers, to prevent any accidental modification of archaeological sites. The use of global positioning system (GPS) technology has greatly assisted the identification of archaeological sites and has been used in the Motuihe Island Archaeological and Historic Assessment report (Dodd, 2003a).

The removal of farm stock from the island has also meant there is a high potential for weed infestation. Since farm stock animals are able to maintain low grassland cover, they help prevent the spread of weeds. Consequently, with the removal of this stock, there is a some pressure to restore the area so that the native vegetation can outgrow and control the weeds. As a rule, tree-planting is not encouraged on or in the vicinity of archaeological sites because trees and their root systems can obscure, damage or destroy archaeological features. Even if archaeological sites are left as open spaces adjacent to tree plantings, there is also the possibility that they may in time become covered with vegetation. As a result, in order to preserve archaeological sites in areas of ecological restoration, there needs to be well-planned and careful management of planting in the vicinity of archaeological sites. Without this, archaeology can be lost forever.

The best preserved sites, situated on the coast and in native bush remnants, will be marked out and excluded from planting, while other sites are planted with the least intrusive vegetation cover (Dodd, 2003a). The entire northwest headland area (roughly 8\% of the island) has also been excluded from planting because of its cultural heritage significance, associated with the quarantine station, internment camp, naval base and cemetery; and because of the camping ground in the area (Dodd, 2003a; 2006b). The Motuihe Trust employs a strict management process regarding the planting of trees (Hawley, 2005). However, despite these management guidelines, there is the risk that unrecorded or currently invisible archaeological sites will be planted on, potentially destroying their features and rendering them largely unobservable. A difficulty is that tree-planting activities are often carried out by well-meaning but poorly informed members of the public who have ecological restoration at the forefront of their minds, rather than archaeology. 
The process of track-making raises similar issues and again the Motuihe Trust has a strict process relating to track-making. The most notable incident concerning archaeology and Motuihe Trust activity occurred on 8 December 2006 when a track was cut along the north-western side of the Snapper Bay stream to facilitate beach access. This resulted in an archaeological site, which contained three midden sites, sustaining some damage (Dodd, 2008). Although consulting with the Auckland Area Manager prior to the work-day, the Motuihe Trust did not notify DoC historical staff of the work to be undertaken. The 30metre track cutting destroyed the most visible surface evidence of the site and little of the site remained intact (Dodd, 2008). Ironically, this accident resulted in the first thorough investigation of an archaeological site on Motuihe. Samples were radiocarbon-dated from the midden sites and were found to have a $95.4 \%$ probability that they dated from between 1410AD and 1640AD (Dodd, 2007). This, however, was an unfortunate incident. Communication between ecological restoration volunteers and archaeologists is essential in making sure that the archaeology of Motuihe Island is appreciated and preserved.

\section{Historical trees or exotic tree-type weeds?}

A second issue to emerge is the tension between exotic trees and ecological restoration. One of the few visible remnants from the activities of residents on the island from the mid$19^{\text {th }}$ century to the early $20^{\text {th }}$ century are the exotic tree plantings. Some of these trees are over a hundred years old and have become iconic features of Motuihe. Because of the trees' age, their associations with important periods of Motuihe's history, and in some cases their rarity, many have been recommended for retention (Dodd, 2003a; 2004). However, these historical plantings come into conflict with the ecological restoration of the island. Many of the historical trees are identified as exotic tree-type weeds which can have a detrimental impact on the ecological restoration programme on Motuihe, as well as on other islands and the mainland. In addition, as exotic trees they do not fit with recreating a piece of New Zealand coastal forest. Consequently, there has been a lot of pressure to remove the historical trees in the context of ecological restoration.

For example, in 2003 there was an instance where a historical group of exotic acmena (Syzygium smithii) trees, forming a hedge on the northwest headland, were removed, as they were deemed to be a nuisance to the ecological restoration. The fleshy fruits of the acmena are appetizing to birds and the seeds can therefore spread quickly, and the trees have the potential to completely replace native forest. It is not known from which period the acmena hedge of trees derived, although it is probable that they were associated with the quarantine station, the internment camp or, most likely, the HMNZS Tamaki Navy establishment period. It was ultimately decided that the acmena trees did not have enough heritage value to be retained, largely because the trees were identified as an "invasive weed species that is likely to become a problem on Motuihe" (Dodd, 2003b: 1). DoC advised that they should be removed and that their removal be somehow mitigated by replacing them with suitable native species which would grow to a similar size and shape. This act embodies the main current focus of the creation of the Motuihe heritage landscape. A group of trees most likely to be associated with the HMNZS Tamaki navy establishment, of which few 
remnants remain, was thus completely removed from the landscape and replaced with native shrubs in order to assist the restoration of the nature heritage of Motuihe Island. More recently, in August 2009, many of the exotic trees on the northwest headland, some of which were given heritage status in Dodd (2004), were cut down for similar reasons.

The Motuihe Trust has also been given permission by DoC to remove seedlings derived from the historical exotic plantings. Several seedlings from exotic species, including the olive trees (Olea europaea), various pine trees, Morton Bay figs (Ficus macrophylla), and Holm oaks (Quercus ilex), have been found on the southern portion of the island (Hawley, 2005). Although the seedlings are related to the historical plantings they are not considered as heritage worthy of protection. In the past these may have been perceived as a way to sustain and preserve the early European association with the island. However, today they are perceived as being in opposition to the restoration of the native natural heritage of the island.

\section{Impact of ecological restoration on seaside recreation}

A third issue relates to changes as to how the island is used by visitors and the visible change in landscape. Motuihe Island is one of the most popular destinations for recreation in the Hauraki Gulf. The popularity of the seaside for recreation is also part of New Zealand's culture of enjoying the sun, sand and water at the beach during summer days. It is a cultural heritage, or way of life, which has been valued in the past and is still highly valued in the present as a tradition to be passed on to future generations.

However, the freedom of recreational users is altered by the re-introduction of endangered birds and reptiles such as native skinks and iconic Kiwi. For example, dog-owners have taken their dogs to Motuihe for decades. However, since the establishment of the Motuihe Project, and with the introduction of bird-species to the island, dogs have been banned from the island because of the risk they pose to introduced native fauna. Even one roaming dog can devastate a Kiwi population. Since Kiwi have been introduced, this prohibition has been stepped up to enforcement as the DoC ranger has become a warranted officer and is therefore able to shoot dogs on sight.

The aim of the Motuihe Project to produce a native forest with flourishing native wildlife is completely transforming the open-pasture appearance of the island. Although areas have been left to be grassland to provide views, as a consequence of planting, the spectacular vistas seen from many points around the island of the Hauraki Gulf will be lost. People will no longer be able to walk over the island and view the contours of the island or the wide panoramic views of the island and the Hauraki Gulf, changing the public's general perception of the island. In the next couple of generations, Motuihe Island will be considered more as an island with a substantial native forest than as an island with open spaces and panoramic views. 


\section{Discussion}

There are challenges in balancing the conservation and protection of cultural heritage with ecological restoration, and these challenges relate to general concerns in island restorations in New Zealand. In Motuihe's case, the native bush remnants are the main heritage features selected to be restored and re-established as the dominant landscape cover, while the cultural heritage of the island appears not to be as acknowledge in the face of ecological restoration. A preferential treatment of natural heritage - including restoration of Motuihe's 'original' natural landscape - compared to cultural heritage, is an expression of the current paradigm in New Zealand heritage management and the current psyche of valuing natural heritage in New Zealand. This situation stems from a nature/culture dualism in heritage management and long established views of what constitutes heritage in New Zealand.

The nature/culture divide is a powerful and pervasive dualism which has influenced heritage management to such an extent that natural heritage and cultural heritage have almost become competing opposites. The dualism forces managers to make 'either/or' decisions about nature or culture with each being perceived to undermine the other when in fact they should be seen as inseparable (Brown, 2008; Feldman, 2004; Lennon et al., 1999). If one considers the notion of ecology and the interconnectedness of every aspect of the world, then it is clear that this distinction is at odds with the interrelated realities of the world. In Lowenthal's (2005: 85) words, "every human relic is also a relic of nature, every aspect of nature altered by human action." In this way, a building (culture) is essentially the same as a bird's nest (nature). Human structures may be more permanent than those of other species, but they can still be considered natural, using materials that are taken from the earth, even if they are often processed. Moreover, the preservation of aspects of nature relies on conservation work undertaken by humans. If nature was truly separate from culture, then there would be no need for the conservation and protection of nature. However, the dualism is well entrenched in heritage management which has meant that places deemed to be natural are created, resulting in cultural heritage aspects often being largely ignored, silenced or not emphasized in order to maintain the perception that the area is in fact natural (Cronon, 2003; Feldman, 2004). Past human presence is partially acknowledged, not acknowledged at all, or quietly removed.

Valuing natural heritage as something to be preserved and restored has become entrenched into the New Zealand psyche. New Zealand has had seven hundred years of intensive landscape change and particularly in the last 150 years there has been a considerable loss of native flora and fauna as a consequence of clearance and the creation of pasture lands (McGlone, 1989; Salmon, 1960; Star \& Lochhead, 2002). This has nurtured a particular attitude towards nature whereby human traces on the natural landscape are considered as regrettable. Such a psyche has also shaped the development of (natural and cultural) heritage management in New Zealand. Natural heritage conservation has attracted much effort and support. Early heritage legislation from the mid- to late $19^{\text {th }}$ century focussed on the preservation of areas of pristine natural beauty as opposed to cultural heritage (Leach, 1991; Nightingale \& Dingwall, 2003; Star \& Lochhead, 2002). The main reason for these calls for natural preservation was the ability of natural heritage - forests, thermal regions, waterways - to attract tourists (Leach, 1991; Star \& Lochhead, 2002). 
Such a legacy has continued into the present with natural heritage having a strong connection with New Zealand's identity and tourism industry. New Zealand's overseas image and tourism industry now ride to a great extent on the scenic natural environment being " $100 \%$ pure" and "clean and green". The natural environment of New Zealand has taken on the mantle of heritage (Kirby, 1996), implying that natural heritage has largely been considered as more important or significant to preserve, restore or conserve than elements of cultural heritage.

Although there is a long history of value towards the indigenous natural heritage of New Zealand (Pawson \& Brooking, 2002), the major change in mentality has been the idea of converting (restoring) good and valuable pastoral land to its perceived original primeval state. Native ecosystem restorations have gained widespread public support over the last two decades and have enjoyed significant political traction; this has been especially evident with the ecological restoration of Motuihe Island and the other islands in the Hauraki Gulf. These restorations have been able to gain funding and volunteer labour by riding the wave of environmentalism prevalent within the present-day society. The ecological restoration of both near-shore and off-shore islands is seen as a way to preserve and recreate what has been lost. In a way, ecological restoration could be seen as an attempt at redemption for the environmental damage caused in the past.

In contrast to natural heritage, cultural heritage has a more recent history of protection and interest. Since New Zealand has been one of the last places in the world to be settled by humans, there has been a perception that it is a young country and that New Zealand's cultural history is not as significant as in other parts of the world. The protection of heritage (particularly settler heritage) took much longer to develop than the protection of natural heritage. It was not until the celebration of settler centennials in the mid- $20^{\text {th }}$ century that cultural heritage conservation was more adequately addressed (McLean, 2000). As a result of these centennials there was a groundswell movement towards the preservation of nationally important cultural heritage in the mid-twentieth century. Various heritage organizations were established, including the New Zealand Historic Places Trust in 1954 and the New Zealand Archaeological Association in 1955.

Although the human history of New Zealand is becoming more appreciated, it still appears to lag behind the widespread support and engagement in the restoration of natural heritage. In general, the restoration of cultural heritage has been hampered by a lack of funding, a lack of interest and a lack of public support (Bade, 2008; McLean, 2000). The preservation of cultural heritage seems to not be as attractive to the public as natural heritage. A native forest with flourishing native birdlife is ostensibly much more pleasing than reading an interpretation sign representing what once was there or viewing an historic building which is no longer used for its original purpose. Ecological restorations literally bring natural history to life. The psychological and emotional motivation behind natural heritage restoration is consequently much stronger than with cultural heritage. A major reason why Motuihe Island (along with other islands) is undergoing an ecological restoration is because of this history of emphasis on natural heritage over cultural heritage and the history of attachment to, and identification with, New Zealand's natural heritage. 
Islandness is another factor which could influence the emphasis of natural heritage over cultural heritage on Motuihe. Although a general heritage issue in New Zealand, this dominance is more clearly seen in the management of island heritage. Islands are often constructed as places which should be 'turned over to nature' as nature sanctuaries (Baldacchino, 2006; Dodds \& Royle, 2003). This association can result in an emphasis towards the preservation of heritage associated with nature.

Physically and psychologically, islandness is regarded as a clear advantage for nature sanctuaries (being nature) and ecological restoration (becoming nature). It is logistically easier to remove mammalian and weed pests from a bounded and separate island landscape and maintain it in this way than on the mainland. Likewise, the distinct journey to an island over water elicits and enhances a feeling of 'getting away from it all' and 'getting closer to nature'. Islands are therefore often constructed as places which are, or should be, turned over to nature. Furthermore, small islands are ideally suited as objects of control and for management exercises (e.g. Redfield, 2000). A bounded and manageable landscape generates the sense of restoring an island of one's own. Such a special sense means the dominant values of the island management group, such as environmental reverence, are often emphasized over other values, such as the retention of material human culture. As a result, it is almost 'natural' for organisations, professional bodies, and spirited individuals to propose alternative and often contrasting interpretations of what belongs on an island such as Motuihe (Stratford, 2009).

As a result, Motuihe Island, and to a large extent, uninhabited or sparsely-populated islands in general, and especially in New Zealand, have been seen through a 'natural' rather than a 'cultural' lens. Islands are often considered as places where natural heritage can be restored, protected and preserved as they are often isolated from human activities which may have detrimental effects on flora and fauna (Potter, 2007). Accordingly cultural heritage is often acknowledged, but is not the focus of restoration activities. In the case of Motuihe, the lack of buildings and structures and its green (mainly grassland) appearance makes it a prime candidate for an island ecological restoration.

\section{Implications and Conclusions}

This paper has sought to illustrate how archaeology, historical trees and recreation have been managed on Motuihe Island, and the definite emphasis on natural heritage in the island's restoration, at the expense of cultural heritage. This dominance, accentuated by the island context, has meant that, to a great extent, Motuihe is constructed as a place of nature, or rather, as a place becoming natural. The natural heritage of the island has been emphasized over the conservation of the history of Maori settlement, and of the colonial and post-colonial histories of the quarantine station, internment camp, children's health camp, navy training facility, farming, and recreational use of the island.

This paper does not oppose the dominance of natural heritage over cultural heritage, nor does it challenge the activities of the Motuihe Trust. Rather, it suggests that this dominance is a phenomenon which warrants study. However, there are concerns, especially among 
cultural heritage practitioners, that there needs to be more of a balance in the preservation and restoration of natural and cultural heritage. As the dominance of natural heritage is bound up in New Zealand's national identity and culture, a solution to this issue, it seems, could be found by heightening the appeal of cultural heritage in places emphasized for their natural heritage. There are, however, many challenges standing in the way, including the perceived inevitability and naturalness of the nature/culture dualism, the simplicity of the dualism for heritage managers, the embeddedness of natural heritage in the New Zealand identity, and the popularity of using islands for nature sanctuaries. There have been suggestions to use natural heritage conservation techniques in cultural heritage management. For example, there has been the suggestion that New Zealand's cultural heritage professionals should devise a "Kakapo strategy", to command a similar sense of urgency to that of saving the Kakapo, a native endangered flightless bird, to account for rapidly disappearing cultural heritage sites (Warren-Findley, 2001: 26).

Managers of natural areas need to appreciate the degree to which nature is influenced and impacted by humans. Everywhere there is, and has always been, an interaction between humans (culture) and the environment (nature). It is therefore unrealistic and unreasonable to create places of nature without taking into account the human history of the place, and making a more balanced representation of the past. Natural and cultural heritage is interconnected and inseparable: "if they are twins, they are Siamese twins, separated only at high risk of the demise of both" (Lowenthal, 2005: 85). It needs to be recognised that cultural values are vital components of areas designated as natural (Lennon, 2000). To acknowledge culture within nature does not mean that nature is less worthy of protection. A human history such as deforestation, farming, and recreation is just as important as ecological processes. By focussing on just one element of heritage (natural or cultural), opportunities are missed to preserve and conserve the historical relationship between people and the environment. We forego cultural heritage if we focus only on natural heritage (Lennon, 2000). Only when we can achieve the appropriate balance between cultural and natural heritage can we preserve and protect heritage in a meaningful and holistic way.

\section{Acknowledgements}

This article is based on the author's MA thesis in Geography for the University of Auckland, entitled "Creating Heritage: the restoration of the heritage landscape of Motuihe Island" (Bade, 2008). Appreciation is expressed to thesis supervisors Hong-Key Yoon and Gretel Boswijk. The author also thanks members of the Motuihe Trust, the Department of Conservation, the New Zealand Historic Places Trust, and the Auckland Regional Council for their time and interest in this research. Gretel Boswijk is especially thanked for her support, guidance and help with developing this paper. 


\section{References}

Bade, D. (2008) Creating Heritage: The Restoration of the Heritage Landscape of Motuihe Island, Master of Arts thesis, Auckland, New Zealand, University of Auckland.

Bade, J. (2006) Sea Devil: Count von Luckner in New Zealand and the Pacific, Wellington, Steele Roberts.

Baldacchino, G. (2006) 'Islands, Island Studies, Island Studies Journal', Island Studies Journal, Vol. 1, No. 1, pp. 3-18.

Brassey, R. (no date) Motuihe: Assessment of Historical and Archaeological Significance, DoC file, DoC 015-40, unpublished.

Brown, S. (2008) Cultural Landscapes and Park Management: A Literature Snapshot: A Report for the Cultural Landscapes: Connecting History, Heritage and Reserve Management Research Project, Sydney, Australia, Department of Environment and Climate Change NSW.

Cronon, W. (2003) 'The Riddle of the Apostle Islands', Orion, Vol. 22, May-June, pp. 3642.

de Lange, P. \& G. Crowcroft (1999) 'The Vascular Flora of Motuihe Island Recreation Reserve', Auckland Botanical Society Journal, Vol. 54, No. 2, pp. 19-29.

Deluxe Charters (2010) Deluxe Charters Trips website, http://www.deluxecharters.co.nz/trips.asp.

Department of Conservation (DoC) (2001) Motuihe Recreation Reserve Hauraki Gulf Marine Park, Auckland, Department of Conservation.

Department of Conservation (DoC) (2010) Department of Conservation website, www.doc.govt.nz.

Dodd, A. (2002) Motuihe Restoration Planting: Archaeological Sites, internal correspondence, DoC 015-40, Vol. 2.

Dodd, A. (2003a) Motuihe Island Archaeological and Historic Assessment, Department of Conservation, unpublished.

Dodd, A. (2003b) Acmena Trees: HNZMS Tamaki Base, Motuihe, internal correspondence, Department of Conservation, unpublished.

Dodd, A. (2004) Exotic Trees of Heritage Significance: Motuihe Island (draft), Department of Conservation, unpublished. 
Dodd, A. (2007) Snapper Bay, Motuihe: Radiocarbon Dates and Analysis of Grab Samples, internal DoC document, Department of Conservation, unpublished.

Dodds, K. \& S. A. Royle (2003) 'The Historical Geography of Islands, Introduction: Rethinking Islands' Journal of Historical Geography, Vol. 29, No. 4, pp. 487-498.

Esler, A. (1974) Inner Islands of the Hauraki Gulf: Motuihe Island, unpublished report to the Hauraki Maritime Park Board, Department of Lands and Survey (L\&S) file, NP 26, Vol. 5.

Feldman, J. (2004) Rewilding the Islands: Nature, History, and Wilderness at the Apostle Islands National Lakeshore, Ph.D. thesis, Madison WI, University of Wisconsin-Madison.

Graham, G. (1930) Te Akarana Maori Association correspondence with the Chief Surveyor of the Lands and Survey, 27 August 1931, Department of Lands and Survey (L\&S) file, NP 26, Vol. 1.

Hauraki Gulf Forum (2008) Tikapa Moana: Hauraki Gulf State of the Environment Report, Auckland, New Zealand, Hauraki Gulf Forum.

Hawley, J. (2005) Motuihe Restoration Plan, Auckland, Department of Conservation.

Heiss-Dunlop, S. (2004) Sustainable Restoration of Motuihe Island, Auckland, Master of Science thesis, University of Auckland, Auckland.

Jones, K. (2007) Caring for Archaeological Sites: Practical Guidelines for Protecting and Managing Archaeological Sites in New Zealand, Wellington, Department of Conservation.

Kirby, V. (1996) 'Landscape, Heritage and Identity: Stories from New Zealand's West Coast' in C.M. Hall \& S. McArthur (eds.) Heritage Management in Australia and New Zealand: The Human Dimension, Melbourne, Oxford University Press, pp. 231-241.

Leach, H. (1991) 'Early Attempts at Historic Site Protection in New Zealand', Archaeology in New Zealand, Vol. 34, No. 2, pp. 83-90.

Lennon, J., Egloff, B., Davey, A. \& Taylor, K. (1999) Conserving the Cultural Values of Natural Areas: A Discussion Paper, Canberra, Australia, Jane Lennon and Associates.

Lennon, J. (2000) 'Conserving Cultural Heritage Values in Natural Areas: the Australian Experience', paper presented to Heritage Economics: Challenges for Heritage Conservation and Sustainable Development in the $21^{\text {st }}$ Century, Canberra, Australian National University, July.

Lowenthal, D. (2005) 'Natural and Cultural Heritage', International Journal of Heritage Studies, Vol. 11, No. 1, pp. 81-92. 
McLean, G. (2000) 'Where Sheep may not safely graze: A Brief History of New Zealand's Heritage Movement 1890-2000' in A. Trapeznik (ed.) Common Ground?: Heritage and Public Places in New Zealand, Dunedin, University of Otago Press, pp. 25-44.

McGlone, M. (1989) 'The Polynesian Settlement of New Zealand in relation to Environmental and Biotic Changes', New Zealand Journal of Ecology, Vol. 12, No. 1, pp. 115-129.

Meadows, M. \& Ramutsinela, N. (2004) 'Conservation, Preservation and Heritage' in J. Matthews \& D. Herbert (eds.) Unifying Geography: Common Heritage, Shared Future, London, Routledge, pp. 305-317.

Motuihe Trust (2010) Motuihe Trust website, www.motuihe.org.nz.

Ministry for the Environment (2004) State of the Environment Report 2004: The Hauraki Gulf, Wellington, New Zealand, Ministry for the Environment.

New Zealand Herald (NZH) (1961) 'Motuihe Looks Back on 140 Years of History', 22 August 1961.

Nightingale, T. \& Dingwall, P. (2003) Our Picturesque Heritage: 100 Years of Scenery Preservation in New Zealand, Wellington, Department of Conservation.

Pawson, E. \& Brooking, T. (2002) Environmental Histories of New Zealand, Auckland, Oxford University Press.

Potter, S. (2007) 'The Quarantine Protection of Sub-Antarctic Australia: Two Islands, Two Regimes', Island Studies Journal, Vol. 2, No. 2, pp. 177-192.

Redfield, P. (2000) Space in the Tropics: From Convicts to Rockets in French Guiana, Berkeley CA, University of California Press.

Rimmer, A. (2004) Tiritiri Matangi: A Model for Conservation, Auckland, Tandem Press.

Rudman, B. (2008) 'Daydream Believers Relive Good Old Days', New Zealand Herald, 19 May 2008.

Salmon, J. (1960) Heritage Destroyed: The Crisis in Scenery Preservation in New Zealand, Wellington, A.H. \& A.W. Reed.

Star, P. \& Lochhead, L. (2002) 'Children of the Burnt Bush: New Zealanders ad the Indigenous Remnant, 1880-1930' in E. Pawson \& T. Brooking (eds.) Environmental Histories of New Zealand, Auckland, Oxford University Press, pp. 119-135.

Stratford, E. (2009) 'Belonging as a Resource: The Case of Ralphs Bay, Tasmania, and the Local Politics of Place', Environment and Planning A, Vol. 41, No. 4, pp. 796-810. 
Tennant, M. (1994) Children's Health, the Nation's Wealth: A History of Children's Health Camps, Wellington, Bridget William Books.

Walsh, L. (1937) Motuihi: The History of Auckland's Lovely Maritime Park, Auckland, Walsh Printing.

Warren-Findley, J. (2001) Human Heritage Management in New Zealand in the Year 2000 and Beyond, Wellington, Ian Axford New Zealand Fellowship in Public Policy.

Wood, M. (ed.) (2006) Guide Notes for the Auckland City Heritage Day, $17^{\text {th }}$ September 2006, unpublished.

Yarwood, V. (1997) 'Break-Out: The Saga of the German "Sea Devil", New Zealand Geographic, Vol. 35, No. 1, pp. 94-112.

Young, D. (2004) Our Islands, Our Selves: A History of Conservation in New Zealand, Dunedin, University of Otago Press. 